\title{
Belief and Superstition of the Bodos of Goalpara, District, Assam
}

\author{
Kajal Dey* \\ Assistant Professor, SCBC College, Murshidabad, West Bengal, India
}

*Corresponding Author: Kajal Dey, Assistant Professor, SCBC College, Murshidabad, West Bengal, India

\begin{abstract}
Belief and superstitions are inseparable part of human society. Every society of the world has beliefs relating to their everyday life and they have specific concept of beliefs too. It is believed that the general populace with fear and admiration and also embodies a practice, custom of society. Every society has its own heritage of traditional knowledge stored in its traditional culture in form of belief, custom and rituals. Although they might appear to be nothing more than belief and rituals far removed from science; they form the basis of the later development in the field of knowledge system even in science and technology. The present paper focuses on the general beliefs of the Bodos of Goalpara District of Assam. The study reveals that some beliefs have meaningful significance but some do not have this kind of notions.
\end{abstract}

Keywords: Belief, Superstition, Witchcraft

\section{INTRODUCTION}

Belief and superstition are the main characteristics of tribal society. Superstition is an unwritten social law. It keeps society intact. It is believed by the general populace with awe and veneration. It embodies a usage, custom or society. Some superstitious believes contains much practical wisdom. It helps in regulating the conduct of life. Sometimes superstition makes man religiously disposed.

There are hundreds of beliefs which are early man had and the tribal society still strongly follows these beliefs. The major beliefs of a tribal man may fall into any of the following categories: (1) evil spirit, (2) magic, (3) taboo, (4) totem, (5) superstition etc.

\section{BELIEF AND ANIMAL}

Animals, beats are also associated with the religious belief of the people. Among the domestic animals first come the bull and cow. The bull is believed to be the carrier of Lord Siva and cow related to Lord Krishna of Hindu mythology, one of the incarnations of Lord Bishnu. For the people cow is also associated with goddess Laxmi, the deity of wealth and prosperity, and therefore very carefully follow the rituals attached to it. The cow dung for the Bodo people are considered scared and used in all household ceremonies. The Bodos clean their houses with a paste made of cow dung and mud. Before propitiation the god and goddess, the Bodo people always cleans their house and courtyard with cow dung. Without doing it, it is felt unclean. The Bodo people never eat beef. But the Bodos who have accepted Christianity takes beef. Otherwise taking beef is asin among the Bodos. However buffalo sacrifice is still prevalent among the Bodos and consumption of the sacrificed buffalo meat as 'prasad' is accepted. Like buffalo, goats are also sacrificed in front of deities and the meat is eaten. Some goats are also set free in the name of god and goddess who are known as Bhevera Burma among the Bodos.

Among the Bodos influence of the cat is greater than other animal. The Bodos believe that witches transform into black cat. If a person sees a cat crossing his road just before setting out on a journey, than it is believed that the journey will be inauspicious one or very bad omen of some dangerous accident. So people go back a few steps and restart the journey after uttering the name of the god. A house will be visited by guests if a cat is seen to be drinking water.

Dogs for the Bodo people in general are not respected and reared in house as it is believed to be unclean and invite bad omens. Digging up of earth in the courtyard by a dog is a bad omen or somebody will die immediately in the family. If a number of dogs barks in chorus than it is believed that some mishap will befall in village or some dire calamity will overtake the village. And if a dog 
moves forward with its hind part touching the ground than some calamity will befall the family. If a female dog embraces domesticity on its own than it is believed that the family will become prosperous in a very short time.

Elephant is seen as god Ganesha himself and when faced reverence is shown by the people who bow down and give food or money as offerings. The Bodo people consider this animal as symbol of luck and prosperity. Similarly if an elephant is seen while venturing out of the house for any new enterprise such as job or any other money related work than there is guarantee that it will be fruitful.

\section{BELIEF AND BIRDS}

Like animals there are so many beliefs and superstition among the Bodos associated with birds and fowls. Among the birds, crows, vulture and even owls are considered as bad omens if they enter the courtyard or sit on the roof of the house. Because the owl is believed to be the career of goddess Laxmi some respect is also attributed to it although the rest are not respected. If an owl cries at night than it is believed to be inauspicious. If a vulture drops excretion in the compound of a house, the householder will come into possession of fortune and then the vulture is considered ass auspicious. If a crow sits in a tree in the compound and cries it is believed that some great calamity will befall the family.

If two fowls fight in house, than it is believed that the house will be visited by guests. If a cock crows in the evening is a bad omen for the family and therefore it is immediately killed and eaten by the family. Red and black cock and chicken are specially dedicated for the propitiation of deity and therefore earmarked for sacrifice. Female chickens are sometimes set free in the name of god after the religious ceremony is over. Killing of these chickens is considered as sin by the Bodo people.

If a cock crows in the evening is a bad omen for the family. So it is immediately killed and eaten by the family.

If a khalilab bird cry out over the sky of the courtyard of a house than it is believed the house will be visited by guests.

The Bodo people believe that the entrance of bees in the house and buildings of its hive there brings wealth and prosperity to the family.

Falling of butterfly on the body of an unmarried girl or boy is an omen of immediate marriage.

\section{BELIEF AND PREgNANCY}

There are so many beliefs related with the pregnancy of an women. Pregnant women always keep a daba (knife) in her hand during her pregnancy up to delivery to protect her from the evil spirit. Because it is believed that the knife is intended to keep off evil spirits. During this time the woman and her husband do not kill any living creature specially ducks, fowls and pigeons because it is believed that her own child in the womb will die if she takes the life of any bird and animal during this period. It is also believed that if a pregnant woman or her husband kills a snake than their child with the same form of abnormality. If during pregnancy the mother is deprived of eating something that she desire the popular believe is that her child will constantly salivate from his or her mouth.

A pregnant woman is not allowed to come outside the house and look at the sun during the solar eclipse. Because it is believed that the baby will born abnormally if the mother look at the sun during solar eclipse.

During the period of pregnancy a woman do not go to the forest. Because it is believed that most of the evil spirits lives in forests and they may be herm her child.

\section{BELIEF IN LIFE CYCLE}

There are a number of beliefs followed by the Bodo people in relation to birth, puberty, marriage, death etc. which are still followed.

\subsection{Birth}

There are a many superstition associated with a pregnant woman. A baby born in the month of Bhadra bears a bad character. If a person born on Saturday or a Tuesday is considered to be so inauspicious that if it looks at anything or say anything than that thing will suffer from the evil mouth. 
The mothers of new born baby always carry a knife with her because it is believed the evil spirit is fearful of iron and so that will not come near the baby. A black spot is given on the forehead of a baby to protect him or her from evil eyes. The mother takes mud from where she urinated, makes a paste and applies it as a spot on the forehead of a newly born baby because it is believed that the evil spirits are frightened of urine, which can be used in the destruction of an evil spirit.

\subsection{Marriage}

There are numbers of folk beliefs and superstition related to marriage among the Bodos. Marriage is thought to be the most important institution in society and so also among the Bodos.

The Bodos follow so many traditional customs at the time of selection of a bride. There are so many beliefs in connection to selection of a bride one of them being if the bride is seen drying or husking paddy than it is believed that the bride will bring fortunate to the family that she is married to. If the bride is seen by the selection party cleaning or sweeping the courtyard or busy at combing her hair, it is believed the bride would have long life. If the bride is seen entering into the main house by putting her left foot at the door than it is believed that the bride would be good nature and be loyal to every one of the family.

Besides the good signs there are beliefs in bad sign also. Such as a mongoose cross the road from the right to the left side in front of the selection party or snake crossing the road from left to right side of the party or seeing dead body on the way are believed to be bad sign.

If the selection party hear the sound of thunder at the time of selection of a bride than it is believed that the prospect of the mission is unfavorable.

If any number of selection party sees the sight of cutting bamboo, a man holding a spade on his arm or working with it than it is believed that either the husband or the wife may die just after the marriage ceremony.

There should be no marriage in the month of Saitra and Pous. Because these months are regarded as very inauspicious. It is believed that if marriage takes place in these months, than misfortune will befall in the happiness of the married couple.

A widow and a barren are not allowed to take a leading part in marriage ceremony because they are regarded as an unfortunate creature.

\subsection{Death}

The Bodo people believe that the soul of a man who meets death by hanging and poisoning or any type of suicide cannot go to heaven.

The death body of a man who meets with death by snake bite should not be burned or buried because it is believed that the soul does not leave the body and Is why the body should be floated on river.

The soul of a dead man does not leave its body and home if the saradu ceremony is not observed by the family.

There is popular belief that barking of boil on the very day of the dismiss of a person prevents in its growth provided that the name of the dead person is uttered while doing the act.

\section{BELIEF AND SPIRITS}

Like the belief of other society the Bodos also believe that spirits cast no shadow on the ground as other things do. And the spirits are believed to have no foot.

The Bodos believed that the fagons (ghost) mostly lives in a bamboo clump. He blows down and shakes the bamboo as a strong blast to frighten a passerby.

The fagons sometimes assumes the form of a man or woman and gives company to a traveler specially in form of a family friend. They follow a traveler and try to frighten him.

The Bodos believe that the spirit who takes a woman away does not always keep her but sends her back to her home.

It is believed by the Bodos that sometimes a male pari visits a woman and vice versa. They make elicit proposals. If the man or woman as the case may accepts the proposal ultimately he or she becomes mad and wasted and later on dies. 
The Bodos believes that the spirits have wives and children like man.

The Bodos believe that except pari other spirits like fagon and biras do not kill man.

The Bodos believe that a person should open a door at night to receive a visitor if the latter calls out thrice to the owner of the house, because it is believed that an evil spirit visits a house at night and addresses a person by his familiar name, but it is believed that he does not call out to him thrice.

The Bodos believed that the spirits afraid in mustard seed, chilies and lemon. Among these things that which is most dreaded by the spirit is mustard grain. It is believed that the sprits are afraid of weapons made of iron and fire also. Besides all these things the spirit especially the fagon is afraid of urine of man.

\section{BELIEFS ANd HUMAN BOdY PART}

Trembling of some parts of the human body like eye, the right side in case of male and left side in case of female is considered a god omen.

If a man beats his elder than it is believed that his hand become shaky.

It is believed that money will come to person whose palm itches.

The Bodo people believe that if men continuously tell lies than the legs of the man will become short.

Among the Bodo people there is a belief that when a child losses his first tooth the tooth should be thrown to the roof of the house which will result in the growing of new strong tooth.

\section{BeLIEF IN TABOOS}

The general mass of the population believe in a number of taboos. The Bodos believe that sleeping during the dusk is inauspicious; the Bodos do not sleep hard towards the north and west because only a dead man's head is placed towards the north or west while cremation or burial. Woman should not comb her hair at the time of thunder. No one should make a sound by lips at night because it is believed that the spirits or the ghost follow the person who make such sound. No one should call out from behind when a person is going to somewhere. The Bodos avoid shaving, hair dressing and cutting nails on their birthday, Tuesday and Saturday because they believe that it decreases the age of a person. Wet cloths should not be kept out during night.

A number of taboos replacing symbolic identification are believed to be appropriate to avoid unwanted incidents by the Bodos. During night snake is called gulao, elephant is called Ganesh baba or $\boldsymbol{b} \boldsymbol{a b u}$, turmeric is called rang, tiger is called Bon raja, sunsui is called guphur etc.

After dark chili, turmeric, money, egg, rice is not given to others to be taken home because it is believed that if these things are given to others at night than goddess Laxmi will leave the home of the giver.

Delicious foods like meat, special curry, cake etc are attached with a piece of chili or burning charcoal to avoid the touch of evil spirit on the way.

\section{BELIEF AND WOMAN}

There are so many beliefs related to woman among the Bodos. A woman with short and ragged hair on the head is believed as unlucky. So that most of the parents of boys do not select these types of girls as a bride for their sons.

A woman should not laugh aloud because it is believed to be a sign of a bad woman.

A Bodo woman do not kill any living creature specially ducks, fowls or pigeons because it is believed that her own child in the womb will die if she takes the life of any bird and animal during this period.

After puberty, girls of Bodo society do not climb a tree because girls were regarded as unclean after puberty. Hence it is believed that a girl or woman by climbing such a tree makes it unclean whereby the tree languishes and later on dies.

Bodo women do not eat any fruits where two are joined together because it is believed that eating of joined fruit will lead to the woman giving birth to conjoined children in future.

\section{BELIEF AND TREE}

Among the Bodo people most of the trees are associated with many beliefs and superstitions. Some trees are associated with traditional god and goddess, worshiping them is an ancient custom of the people as well as the Bodos. The Siju tree is recognized as sacred abode of God Bathou. Basil plant is also a sacred plant which is worshipped by the Bodos. The mango and bel trees are most important 
trees for the Bodo people. The leafs are thought to be sacred and are used in all types of celebration from the birth to death of a person in the society.

On the other hand some are associated with evil spirits. It is believed that the large trees are abode of evil spirits. fagons lives in bamboo plantations. It is believed that the witches keep their soul in brooms. The witches and the evil spirits are afraid of thorny branch. The Bodos believe that if a person commits suicide by hanging from a tree, the tree becomes his home.

\section{BELIEF IN RELATION TO METAL}

Among the Bodo people metal plays an important role in their day to day life. Among the metals gold and silver plays the most important role. It is not only the sign of richness and ornamental beauty but also symbol of good omen for individual and family. To lost and find gold both are bad omen for man. Gold with some stone avoids evil eyes. Gold or silver is compulsory in marriage which is presented to the bride from the groom. Initiation ceremony and some rites involve application of gold. Gold is thought to be sacred and use to purify home in rituals with water and basil leafs.

Iron is also related with a number of beliefs of the Bodo people. Iron on the body or in the hand avoids effects of evil spirits. That is why pregnant woman always keep knife of iron in their hand. People always go with iron tools in jungles to avoid from evil spirits.

Sometimes ojhas prescribe iron ornament for sick person as resistance for farther attack by evil spirits.

Among the important materials, brass is also plays an important role in the Bodo society. The houses signified as poor who do not have at least a few utensils of brass. In annaprasnna and in marriage the bride is mostly presented with the brass utensils which felt to be a respected gift. Bells of brass are used in temples.

The household materials of different metals are equally respected and dedicated in their traditional occasions.

\section{BELIEF IN WITCHCRAFT}

Like others the Bodos are also believe in the efficacy of witchcraft and afraid of them. Most of the tribal and non tribal groups beliefs and practice witchcraft. Nearly all societies have some concept of witchcraft, in that certain individuals are thought to have supernatural powers, which may be used to do harm. If we look for the word witchcraft in a dictionary, we will see that it is the art of bringing magical power to bear, or at least of trying to do so.

Belief in witchcraft from part of a magical world view in which powers and forces inherent in the universe may be directed for good or ill. This is a world where everything is seen in terms of spirits and were certain persons specialized in their control. The magic workers have been called by many different names, most commonly witches, magicians and sorcerers. The word 'dainii' and 'bhutuni' bears the meaning of witch and sorcerer in Assamese society. In Bodo society it is known as daina or daini. No difference is found between witch and sorcerer in Assam in general, however witches are usually female, associated with darkness and night time, and with the reversal of normal life. But among the Bodos it is seen that besides old woman, young women and men are also involved in practice witchcraft. Witches are also commonly believed to have spatial spirit animals or familiars such as black cats newts and snakes that perform services for them. They have also knowledge of plants and herbs, and they concoct their spells using a giant or cauldron. Having all manner of spatial abilities, they are thought to able to change their shape, fly and sometimes trick and deceive. A witch is often believed to be capable of being in two places at once. She can act at night while her physical body lies sleeping at home.

The Bodos believe that the witches use magic to harm and bewitch specific people. It is believed that the witches inserted small things into the victims body that would make him or her fall ill and ultimately die counter magic was applied in time. It is also believe that the witches use magic to herm and bewitch specific people. The witch collects cloths, hairs, nails and other things used by the people whom she wants to do herm herself, sometime with the help of other persons. Then she mixed other things with it and buries them at the entrance of victim's homestead. After that the victim falls ill and slowly destroyed by the witch, as the people believe. It is believed that before a woman or a man was admitted to the group she/he had to prove that she had caused the death of close relative, preferably her own child. It is believed that a witch always try to obtain an object connected with the person they 
want to harm, such as hair, spittle or nails, cloth etc. it is also believe that the witches can send caterpillars or grasshoppers to destroy crops, and they may send insects into the body of a victim to destroy it.

Precautions to avoid being bewitched included a person regulating his or her life so that a witch was unlikely or unable to attack. This often involved moving out of a witch infested area. Or refusing to allow those thought to be witches to live nearby. In tribal societies of Assam fear of witches acted as a sanction enforcing neighborly conduct. Alternatively, cutting all contact and avoiding the borrowing or lending of objects through which witches might work magic was another option. It was considered dangerous to receive a gift from a witch as this might cause misfortune.

\section{THE OJHAS}

Witchcraft is an activity that cannot be detected by everyday means, and so the action of witches have to be discovered by divination. Some divination is revealed to men or women who are thought to have special powers and who speak as the medium of the spirits. They are expert of magic and charms. It is believed that the diseases caused by witches can be removed by medicine man or ojhas only. It is often the job of medicine man to remove the object that has caused by the witches. The ojhas are diviner and a magician who exposed witches and cleared areas of witchcraft. The people believed that witches brought sickness and death at any time and sought to control their evil powers. An ojha is the one who knows what medicine to use to be able to see witchcraft with his own eyes and how to drive it away. Ojhas held public séances at which they danced and divined, usually at the request of someone who is suffering or feared misfortune. The Bodos believed that out of jealousy to a man being rich, earning fame or living happily with children or to take revenge against enemies, some fellow villagers try to do harm through witchcraft or black magic. In doing so the witch take resources of magico-religious performances under the door step of man to whom he/she wants to harm. These preparations also include, as the villagers described, pieces of nails, hair and pieces of clothes of that person whom he/she wants to harm. To get rid of this, the affected man takes the help of ojha who can locate the position where the medicinal has been placed.

\section{CONCLUSION}

The folk beliefs and superstition are deep rooted on the tribal as well as on the Bodo society. They are far from the enlightened and modern society, mostly they do not explain anything with logic. In the above discussion it is revealed that the beliefs and superstitions are the main characteristics of a tribal society. Superstition is an unwritten social law. It keeps society intact. It is believed by the general populace with awe and veneration. It embodies a usage, custom or etiquette of society. Some superstitious believes contains much practical wisdom. It helps in regulating the conduct of life. Sometimes superstition makes man religiously disposed.

\section{REFERENCE}

[1] Barua, Birinchi Kumar: 1996. Axomor Laka Sanskriti: Guwahati.

[2] Bordoloi, Nirmal Prabha: 1996. Axomor Laka SanskritI: Guwahati.

[3] Brahma, Binay Kumar: 2012. Assamni Somaj Harimuao Subang Futhainai: Kokrajhar

[4] Brahma, Kameswar: 1989. Aspects of social Customs of the Bodos: Kolkata

[5] Brahma, kameswar: 1992. A study of socio religious Beliefs, Practices and Ceremonies of the Bodos: Calcutta.

[6] Das, Dhiren: 1994. Goalporiya Laka Sanskrit Aru Lakageet: Guwahati.

[7] Dutta, B.: 1995. AStudy of Folklore of Goalpara Region of Assam: G.U.

[8] Greenwood, Susan and Airey, Raje: 2006. witchcraft and Practical magic: London.

[9] Narji, Bhoben: 2010. Boro Kocharini Somaj Aru Harimu: Kajalgaon.

[10] Rabha, Malina Devi:2011. Assamar Janajati Aru Sanskriti (ed): Jorhat.

[11] Rajkhowa, Benudhar: 1973. Assamese Popular Superstitions and Assamese Demonology:G.U.

Citation: Kajal Dey. "Belief and Superstition of the Bodos of Goalpara, District, Assam”. International Journal of History and Cultural Studies (IJHCS). vol 5, no. 1, 2018, pp. 59-64. doi: DOI: http://dx.doi.org/ 10.20431/2454-7654.0501006.

Copyright: (C) 2019 Authors. This is an open-access article distributed under the terms of the Creative Commons Attribution License, which permits unrestricted use, distribution, and reproduction in any medium, provided the original author and source are credited. 